\title{
Postpartum depression and its accomplices in Peshawar; a metropolitan city of Pakistan.
}

1. MBBS, FCPS Consultant Gynaecologist $\mathrm{CMH}$ Multan

2. MBBS, MPH

Consultant CMH Sargodha

3. MBBS, MCPS, FCPS

Consultant Gynaecologist $\mathrm{CMH}$ Lahore.

4. MBBS, MCPS, FCPS Consultant Physician $\mathrm{CMH}$ Rawalpindi.

5. MBBS, MCPS, FCPS Consultant gynaecologist PNS Shifa Hospital.

6. MBBS, MCPS, FCPS Consultant gynaecologist PNS Shifa Hospital.

Correspondence Address: Dr. Afeera Afsheen

Consultant Gynaecologist Surgeon Combined Military Hospital Multan afferaafsheen1977@gmail.com

Article received on:

14/09/2020

Accepted for publication:

$24 / 11 / 2020$

\begin{abstract}
Afeera Afsheen ${ }^{1}$, Khaula Atif Khan², Javaria Nosheen ${ }^{3}$, Sobia Mehreen ${ }^{4}$, Rabiah Anwar, Bushra Iftikhaar ${ }^{6}$

ABSTRACT... Objective: To analyze prevalence and severity of postnatal depression among females of a major but socio-culturally traditional city of Pakistan, with an aim to pinpoint eminent demographic and medical accomplices. Study Design: Cross Sectional Study. Setting: Combined Military Hospital Peshawar. Period: Feb 2016 to Feb 2017. Material \& Methods: Sample was collected via random probability technique. A self-designed questionnaire was used; encompassing demographic details and information regarding obstetric and family history. Screening tool was Standardized "Edinburgh Postpartum Depression Scale (EPDS)". Descriptive analysis done via SPSS-21. Outcome variable (EPDS) was cross-tabulated with independent variables, correlations were generated by Pearson 2-tailed bivariate analysis; p-value $<0.05$ was considered as significant. Results: Response rate was $52.2 \%$ (n-402). Low, moderate and high risk patients for developing depression were $27.1 \%(n-109), 15.4 \%(n-62)$ $\& 12.9 \%(n-52)$ respectively. There was a strong relation between outcome and age $(p<0.001)$, education $(p-0.001)$, socio-economic class $(p-0.013)$, bad obstetric history $(\mathrm{BOH})(\mathrm{p}-0.009)$, age of Last Child Born(LCB) $(p-0.010)$, mode of delivery $(p-0.011)$, postpartum phase $(p<0.001)$ and postpartum complications $(\mathrm{p}-0.003)$. Number of sons was negatively correlated with EPDS scores (Pearson correlation co-efficient -0.128 and $p-0.01$ ). There was no significant impact of years since married ( $p-0.349$; husband's education ( $p-0.397)$, number of children ( $p-0.966)$ or daughters ( $p-0.063)$ and previous offspring's death ( $p-0.076)$. Conclusion: Considerable risk of developing postpartum depression was detected among the respondents. Sociodemograhic aggravators were identified to be maternal age, less interpregnancy interval, delivery by SVD, gender of children and postpartum complications. Postpartum depression can be detected by screening/diagnosing every postnatal woman and then promptly treating the sufferers. Imperative measures are opined to identify and vigorously address the sociodemographic and medical aggravating factors. Collaboration of psychiatrists/psychologists is highly recommended in obstetric set-ups.
\end{abstract}

Key words: $\quad$ Female Reproductive Health-Care, Mother-Child Health, Postnatal Period, Prenatal Care, Under-Developed Countries.

Article Citation: Afsheen A, Khan KA, Nosheen J, Mehreen S, Anwar R, Iftikhaar B. Postpartum depression and its accomplices in Peshawar; a metropolitan yet traditional city of Pakistan. Professional Med J 2021; 28(8):1147-1155. https://doi.org/10.29309/TPMJ/2021.28.08.6078

\section{INTRODUCTION}

Depression is a great contributor to disease burden worldwide; unfortunately there is substantial treatment gap between developed and developing nations. Like other mental health issues, depression is still a stigma for many, it frequently remains under-diagnosed, denied or even defied by majority. Females are linchpin to any society; they face unique challenges during child-bearing age most of which relate to health and disease. Female reproductive health issues often remain neglected. ${ }^{1}$ Situation for postnatal mental state of women is analogous to other psychiatric problems ${ }^{2-6}$, they are seldom screened or treated. Mothers play a pivotal role in raising their children. Depression does not only affect them, it also impedes maternal-infant bonding. Psychological, cognitive and emotional development of offspring of depressed mothers is often hampered. Once mature, such children seldom render their best to any community. ${ }^{7}$ Postpartum period is divided into 3 main phases; immediate, 2-6 weeks and more than 6 weeks postpartum. ${ }^{8}$ Each era fetches its own 
physical, mental and socioeconomic challenges. Postpartum depression (PPD) is defined as depressive disorder with onset within 6 weeks of parturition. ${ }^{9}$ Basically, 2 weeks to 6 months after delivery is the most appropriate time to screen for PPD. Several screening tools are available; EPDS is a validated 10 -items questionnaire. It is a reasonably accurate with a decent internal consistency; and is one of the most frequently used screening tool..$^{10-15}$ An EPDS score of $\geq 12$ raises suspicion of PPD. Postpartum Depression Screening Scale is another commonly used self reporting inventory, but it is less precise than EPDS with a higher false-positive rate. ${ }^{9}$

PPD has been extensively studied in many parts of the world. Its prevalence is highest in under-developed countries.,16 In Western literature it varies from $11-19 \% .^{12,17}$ Pakistan is a traditional country; Peshawar is one of her most contemporary yet a conventional city; with a sizable population of 3.5 million. In province of Khyber-Pakhtun-Khwah (KPK), lush and vivid cultures are nurtured since ages; which often over-shadow the medical evidence and practices. This frequently results in adversities to health and disease related outcomes. Gender bias against women is unambiguous here. It's an enigma that in many customary areas, provision of medical services to females is often taken as a matter against pride or prestige. Males feel ashamed if reproductive health issues of their ladies are discussed with any outsiders like medical/paramedical staff, embarrassment is even worsened when it comes to psychological/ psychiatric problems. It's a dilemma that these women are often entitled to services of local unqualified midwives at the maximum. Postnatal phase makes such women more prone to succumb to mental health challenges, especially depression. In Pakistan, PPD has ranged between $17 \%$ to $63 \%{ }^{4,6}$, is thus highest in Asia. ${ }^{6}$ These alarming figures could not yet gather passable attention of researchers, particularly in KPK.

Hence authors up took this study to see incidence and contributing factors of postpartum depression in Peshawar. In this study, it was hypothesized that there must be substantial prevalence of
PPD in target population and very commonly encountered demographic and medical features like advance maternal age, poor socioeconomic status, lower education level, lesser no of male children and post-partum complications like excessive bleeding,wound infection etc were suspected as potential accomplices. It was the first study of its type from Peshawar and was expected to yield interesting results. Basing on these data, researchers may evaluate similar populations of the country and define corrective measures to manage PPD.

\section{MATERIAL \& METHODS}

This Cross-sectional, descriptive study was conducted at Combined Military Hospital Peshawar, from Feb 2016-Feb 2017. Sample was collected utilizing random probability technique. A self-designed questionnaire was used encompassing demographic details and information regarding mode of delivery and current family members, medical and past history, post-partum complications like $\mathrm{PPH}$, wound infection and sepsis. Standardized "Edinburgh Postpartum Depression Scale (EPDS)" was used as inventory. Formal approval from institutional review board was taken.

All Females who had delivered in subject hospital or those reporting for postnatal follow up were enrolled after endorsing informed consent. Women with severe language barrier, with history of or diagnosed with depression or any other mental health ailment like manic depressive psychosis etc were excluded. Women already diagnosed with debilitating medical illness like liver disease, pulmonary disease or substance abuse were also excluded.

To enhance comfort/confidence only lady doctors fluent in local languages of respondents assisted them to fill the questionnaires. Provision of closed spaces within hospital ensured privacy and confidentiality. Simpler demographic questions preceded obstetric details. Finally EPDS was filled.

Required sample size for 3.5 million was 385 (keeping margin of error $5 \%$, confidence level 
95\% and response distribution 50\%). Catering for a estimated non-response rate of $50 \%, 770$ forms were distributed. Data analyzed via descriptive analysis (SPSS-21), qualitative data expressed as frequencies/percentages; quantitative as mean \pm standard deviation (maximum/ minimum). Main outcome variable(EPDS score) was cross-tabulated with independent variables(age, client's education, husband's education, years since married, socioeconomic class, number of children/daughters/sons, age of last child born(LCB), history of offspring's death, bad obstetric history $(\mathrm{BOH})$, mode of delivery(spontaneous vaginal delivery-SVD vs. Caesarean section, days since delivery, postpartum complications including wound infection, postpartum hemorrhage-PPH and fetal/ neonatal death or other serious health problems). Cross-tabulation done via Chi-square, while Pearson correlation co-efficient was generated

\begin{tabular}{|c|c|c|c|c|c|c|c|}
\hline \multirow{2}{*}{ Variable } & \multirow{2}{*}{ Category } & \multirow{2}{*}{$n(\%)^{1}$} & \multicolumn{4}{|c|}{ Risk of Developing Depression } & \multirow{2}{*}{ P-Value } \\
\hline & & & Minimal & Low & Moderate & High & \\
\hline \multirow{3}{*}{ Age (Years) } & $<19$ & 14(3.5) & 14 & 0 & 0 & 0 & \multirow{3}{*}{$<0.001$} \\
\hline & $20-29$ & $210(52.2)$ & 112 & 54 & 28 & 16 & \\
\hline & $\geq 30$ & $178(44.3)$ & 53 & 55 & 34 & 36 & \\
\hline \multirow{3}{*}{ Education (Grades) } & $<5$ & 88(21.9) & 54 & 11 & 11 & 12 & \multirow{3}{*}{0.001} \\
\hline & $5-10$ & $222(55.2)$ & 88 & 72 & 40 & 22 & \\
\hline & $\geq 11$ & $92(22.9)$ & 37 & 26 & 11 & 18 & \\
\hline \multirow{3}{*}{$\begin{array}{l}\text { Socio-economic Class } \\
\text { (SEC) }\end{array}$} & Low & $328(81.6)$ & 143 & 98 & 49 & 38 & \multirow{3}{*}{0.013} \\
\hline & Middle & $58(14.4)$ & 29 & 9 & 7 & 13 & \\
\hline & Upper & $16(4.0)$ & 7 & 2 & 6 & 1 & \\
\hline \multirow{4}{*}{ No of Children } & Nil & $30(7.5)$ & 16 & 0 & 14 & 0 & \multirow{4}{*}{$<0.001$} \\
\hline & $1-2$ & $164(40.8)$ & 86 & 43 & 12 & 23 & \\
\hline & $3-4$ & $164(40.8)$ & 59 & 61 & 19 & 25 & \\
\hline & $>4$ & $44(10.9)$ & 18 & 5 & 17 & 4 & \\
\hline \multirow{4}{*}{ No of Daughters } & Nil & $72(17.9)$ & 58 & 0 & 14 & 0 & \multirow{4}{*}{$<0.001$} \\
\hline & $1-2$ & $254(63.2)$ & 92 & 83 & 40 & 39 & \\
\hline & $3-4$ & $46(11.4)$ & 11 & 21 & 5 & 9 & \\
\hline & $>4$ & $30(7.5)$ & 18 & 5 & 3 & 4 & \\
\hline \multirow{4}{*}{ No of Sons } & Nil & 134(33.3) & 54 & 32 & 26 & 22 & \multirow{4}{*}{$<0.001$} \\
\hline & $1-2$ & $242(60.2)$ & 113 & 77 & 22 & 30 & \\
\hline & $3-4$ & $12(3.0)$ & 12 & 0 & 0 & 0 & \\
\hline & $>4$ & $14(3.5)$ & 0 & 0 & 14 & 0 & \\
\hline \multirow{2}{*}{$\mathrm{BOH}^{2}$} & No & $388(96.5)$ & 175 & 106 & 61 & 46 & \multirow{2}{*}{0.009} \\
\hline & Yes & $14(3.5)$ & 4 & 3 & 1 & 6 & \\
\hline \multirow{4}{*}{$\begin{array}{l}\text { Age of Last Child Born } \\
\text { (Years) }\end{array}$} & Nil & $72(17.9)$ & 34 & 17 & 15 & 6 & \multirow{4}{*}{0.010} \\
\hline & $<2$ & $152(37.8)$ & 61 & 57 & 17 & 17 & \\
\hline & $3-7$ & $152(37.8)$ & 68 & 32 & 28 & 24 & \\
\hline & $>7$ & $26(6.5)$ & 16 & 3 & 2 & 5 & \\
\hline \multirow{2}{*}{ Type of Delivery } & SVD $^{3}$ & $242(60.2)$ & 99 & 64 & 49 & 30 & \multirow{2}{*}{0.011} \\
\hline & C- $\mathrm{Sec}^{4}$ & $160(39.8)$ & 80 & 45 & 13 & 22 & \\
\hline \multirow{4}{*}{$\begin{array}{l}\text { Post-natal Complication } \\
\text { (Maternal or Fetal/ } \\
\text { Neonatal) }\end{array}$} & Nil & $356(88.6)$ & 154 & 101 & 56 & 45 & \multirow{4}{*}{0.003} \\
\hline & Wound Infection & $16(4.0)$ & 4 & 5 & 3 & 4 & \\
\hline & $\mathrm{PPH}^{5}$ & $14(3.5)$ & 5 & 3 & 3 & 3 & \\
\hline & Others $^{6}$ & $16(4.0)$ & 16 & 0 & 0 & 0 & \\
\hline
\end{tabular}

Table-I. Study variables which casted significant impact on risk of developing depression (n-402). by 2-tailed bivariate analysis; $p$-value $<0.05$ was considered as significant.

\section{RESULTS}

Response rate was $52.2 \% \quad(\mathrm{n}-402)$; all respondents were married as stated; 5.7\% (n23), 30.3\% (n-122) and 63.9\% (n-257) were interviewed at $<2$ weeks, 2-6 weeks and $>6$ weeks of delivery respectively. Quantitative variables were; Age (years) 28.03 \pm 5.253 (16/39); Client's Education7.43 \pm 4.956 (0/16); Husband's Education $(10.84 \pm 2.785(0 / 16)$ and Years since married $7.97 \pm 4.730(1 / 19)$.

EPDS scores were $7.57 \pm 5.563(0 / 27)$; Low, moderate and high risk participants were $27.1 \%$ (n-109), 15.4\% (n-62) \& 12.9\% (n-52) respectively. Table-I demonstrates qualitative variables having significant relationship with EPDS grades. 
1. $n$ stands for Frequency and \% for Percent

2. BOH stands for Bad Obstetric History

3. SVD stands for Spontaneous Vaginal Delivery

4. C-Sec stands for Caesarean section

5. PPH stands for Post-Partum Haemmorhage

6. Others means foetal/neonatal death or serious disease

There was a strong relation between risk of developing depression with age $(p<0.001)$; older patients were at higher risk; client's education(p-0.001), less educated had lower chances of depression; number of children $(p<0.001)$, clients with less than four children were mostly at low risk of depression, bad obstetric history(p-0.009), with positive impact of $\mathrm{BOH}$ on EPDS scores, age of LCB(p-0.010), high risk clients increased with age of LCB; type of delivery(0.011), 32.6\% of patients with SVD had moderate to high risk of depression as compared to $21.8 \%$ patients with caesarian section done.

There was a significant negative correlation between number of sons and EPDS-scores (Pearson correlation co-efficient -0.128 and

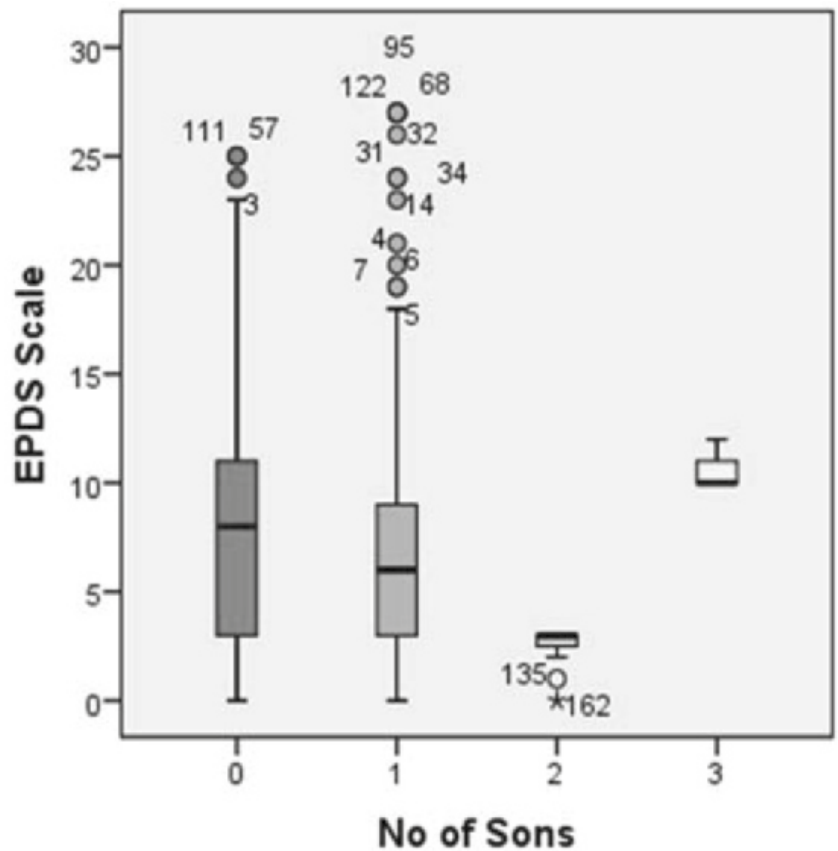

$\mathrm{p}-0.01)$. Figure-1 illustrates that that scores of EPDS were higher, more variable and heterogeneous among subjects with lesser sons; whereas the respondents without daughters had least scores, and those with daughters had more scores without considerable difference in invariance or consistency. None of respondents with more than 2 sons or without daughters had severe depression; while $19.4 \%$ and $16.4 \%$ of those no sons had moderate and severe depression respectively.

A U-shaped trend was observed on comparing outcome with SEC (p-0.013) and postpartum phases $(p<0.001)$; maximum and minimum risks were disclosed by middle-class and 2-6 weeks postpartum respectively (Figure-2), 34.8\% participants who reported in first postpartum phase had severe depression. Similarly, only $3.48 \%$ and $11.4 \%$ clients documented $\mathrm{BOH}$ and postpartum complications respectively, nevertheless, $50 \%$ of former ( $p-0.009)$ and $28.2 \%$ of later had depression (p-0.003). 32.6\% of those who underwent SVD ( $p-0.011)$ were more susceptible.

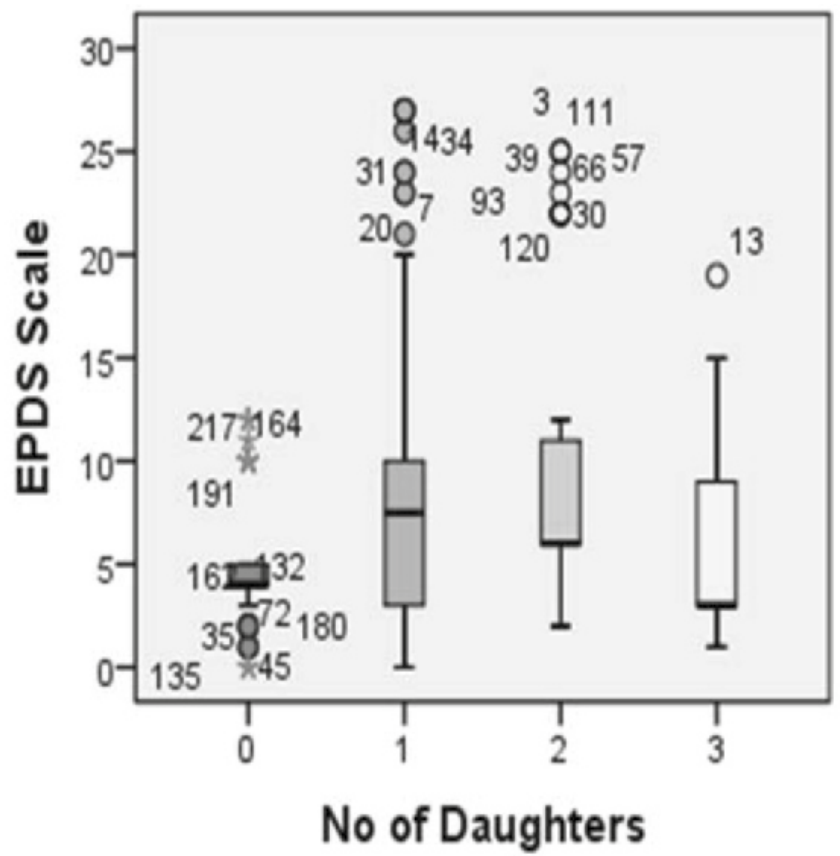

Figure-1. Boxplots illustrate that subjects without sons or no daughters showed highest and lowest EPDS scores respectively. 

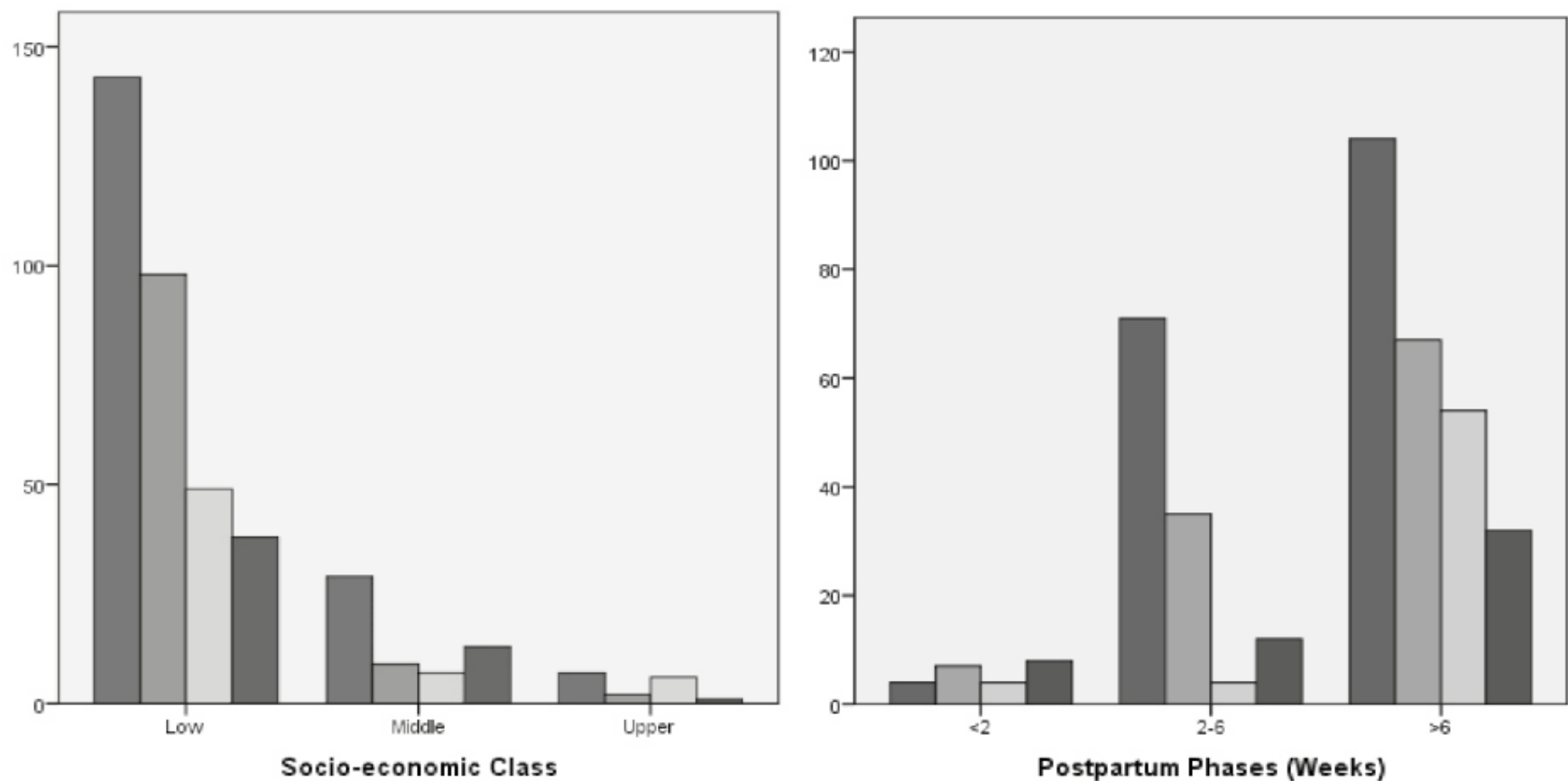

Figure-II: U-shaped trend of post-partum depression in respondents reporting from various socio-economical classes and in different postpartum phases.

There was no significant impact of years since married ( $p-0.349)$; husband's education ( $p-0.397)$ and any previous offspring's death (p-0.076).

\section{DISCUSSION}

Health is a state of comprehensive physical, mental and emotional wellbeing. Healthy individuals validate efficacious nations. Healthcare facilities are not a prerogative of women in many conventional communities; they are rather the prime victim to impose socio-cultural practices. ${ }^{1,18}$ Reproductive health matters of women are no exception. ${ }^{1} \mathrm{~A}$ mother is the nucleus of every family. Majority of females, especially in under-developed countries, opt for motherhood, which inevitably taxes their health for particular durations. Postpartum phase is described as the fourth stage of labour. ${ }^{8}$ It's one of the most demanding periods for every woman. Postnatal depression (PPD) is a common mental health phenomenon. ${ }^{4,6,19}$ Patients having physical complications as an aftermath to pregnancy or delivery accede more to psychological trauma. ${ }^{8}$ Psychosomatic insults of PPD may manifest as mere inability to perform daily activities of life to even suicidal tendency. ${ }^{12,20-22}$ Spectrum of behavioral effects of PPD may persist up to 5 years or more.$^{23} \mathrm{~A}$ mother's role in up-bringing of her children can never be over-emphasized. PPD may cast explicit effects on mother-child health. Physical and mental growth of children especially the infants of depressed mothers is inexorably jeopardized. ${ }^{4,6,19,22-25}$

In this study, $27.1 \%$, and $28.3 \%$ respondents carried low and moderate/severe risk of PPD respectively. Globally prevalence of PPD has persisted as 10-15\% ${ }^{11,13,23,26}$, ranging from 0-60\%. ${ }^{11}$ Literature supports its high occurrence in underdeveloped countries. ${ }^{25,27-29}$ In Asia, PPD is $3.5-63.3 \%$; ${ }^{14}$ being reported as $17.3 \%{ }^{5}, 28.8 \%^{4}$ and $28-63 \%$ by researchers from Pakistan. Among Asian countries, it is highest in Pakistan and lowest in Malaysia. ${ }^{14}$ In India, one research documented $44.6 \%$ and $46.9 \%$ depression in immediate postpartum and 6-8 weeks postpartum women respectively; ${ }^{3}$ another endorsed its prevalence as $23 \% .^{30}$ In Bangladesh and Nepal it was $22 \%{ }^{31}$ and $12 \%{ }^{15}$ respectively; while in China and USA it is as low as $8.2 \%^{10}$ and $11.4 \%$ respectively. ${ }^{12}$ Halbreich et al proclaimed quite Iow PPD in Austria, Denmark and Singapore; and a much higher incidence in Brazil. Italy and South Africa. ${ }^{11}$ 
In this study, $52.1 \%$ and $33.5 \%$ of patients reporting in first and third postpartum stages were more depressed. Depression scores were positively correlated with maternal age, education and age of LCB. More predisposed belonged to middle class, had $\mathrm{BOH} /$ postpartum complications or had underwent SVD. There was no significant impact of husband's education, years since marriage or death of any previous offspring.

Researchers have described impacts of various demographic and medical features on PPD. 4,14,16,21,32-34 Poverty is a major association; 11,14,20 with a surge of PPD in low/middle income countries. -6, $16,21,32,33$ In South-east Asia, $18-30 \%$ of urban and $28-36 \%$ rural populations harbor it. ${ }^{32,33}$ Unplanned pregnancy as well as verbal abuse and domestic violence of the mother/ children augmented it. ${ }^{4,30}$ Breast feeding problems ${ }^{4,5,13,25}$ limited social support ${ }^{5,11,26,36}$ and stressful events during pregnancy ${ }^{26,34,36}$ are other contributory factors. Scientists have also compared the effects of SVD to C-section on physical and mental statuses of women. ${ }^{8}$

In Pakistan, socio-cultural and environmental factors magnify PPD; 6,11 Pakistani women living in countries other than Pakistan also harboured exacerbated levels. ${ }^{6}$ In India, lower socioeconomic status, multi-parity and congenital anomalies are major risk factors. ${ }^{20,27,30}$ Confrontational relations, adverse events during pregnancy and lack of physical also intensify it. ${ }^{30,37}$ Scientists from China negated any significant impacts of maternal age or education, per capita income, unplanned pregnancy or pregnancy/delivery related associations on PPD. ${ }^{10}$

This study asserted relation between son preference and severity of depression. Ironically, there were no high risk women among those who had no daughters or had 3 or more sons; while $35.8 \%$ of those without a son revealed moderate/severe depression. Penchant for sons is quite apparent in many societies of the world ${ }^{38}$, especially in Pakistan. ${ }^{18}$ Daughters have been claimed to enhance PPD on their arrival. ${ }^{27,30}$
It was never advisable to confine the management of female reproductive health issues by midwives or gynecologists alone. A multidisciplinary approach to manage gestational and postpartum issues has been considered by many clinicians. Screening and treatment of PPD are becoming obligatoryin everyobstetricset-up. ${ }^{17}$ Electronicand social media have been utilized at limited scales. Interventions like psycho-pharmacotherapy are well investigated; internet based psychotherapy for PPD is an upcoming module. ${ }^{39}$

This research carried few limitations. Generalizability of results is questionable due to integration of a single health-care institution. Incorporation of additional variables and interviews of spouse/family members of respondents could alter the interpretations. Pre-pregnancy/antenatal screening and serial postpartum scores could yield better inferences.

Nevertheless, this study is distinctive and first of its kind as no similar study has yet been carried out in Peshawar or other cities of relevant province as per the meager knowledge of the authors. Questions posed were proved to be precise and considerable glance of pertinent influential factors was acquired. It was unique to incorporate EPDS; a user-friendly and precise inventory. The study unmasked the tip of a probable iceberg; and as a pioneer report from the concerned region, it provided with a way-forward to carry out similar researches with better modules locally or globally.

\section{CONCLUSION}

PPD casts perpetual and detrimental effects on individuals, their families as well as societies. Obstetric management can hardly suffice without psychological mediation. It is mandatory to prevent and preclude PPD by paying due attention to every possible responsible factor in all pregnancies. Screening for depression using standard inventories like EPDS shall be made customary in antenatal and postpartum packages. Multidisciplinary psychosocial interventions for PPD must be advocated in maternal welfare programmes. To temper socio-cultural pressures on females, evidence based medical practices must be preached in every health care set-up. 
Copyright $\odot 24$ Nov, 2020.

\section{REFERENCES}

1. Atif K, Naqvi S, Hassan SN, Ehsan K, Niazi S, Javed A. Reproductive health issues in Pakistan; do myths take precedence over medical evidence? J Pak Med Assoc. 2017; 67(8):1232-7.

2. Murray C, Vos T, Lozano R, AlMazroa MA, Memish ZA. Disability-adjusted life years (DALYs) for 291 diseases and injuries in 21 regions, 1990-2010: $A$ systematic analysis for the Global Burden of Disease Study 2010. The lancet 380.9859 (2012): 2197-2223.

3. Eaton J, McCay L, Semrau M, Chatterjee S, Baingana F, Araya $R$, et al. Scale up of services for mental health in low-income and middle-income countries. Lancet. 2011; 378(9802):1592-603.

4. Ali NS, Ali BS, Azam IS. Post-partum anxiety and depression in peri-urban communities of Karachi, Pakistan: A quasi-experimental study. BMC Public Health. 2009; 9(1):384. doi: 10.1186/1471-2458-9-384.

5. Shah S, Lonergan B. Frequency of postpartum depression and its association with breastfeeding: A cross-sectional survey at immunization clinics in Islamabad, Pakistan. J Pak Med Assoc. 2017; 67(8):1151-6.

6. Gulamani SS, Shaikh K, Chagani J. Postpartum depression in Pakistan. Nurs Womens Health. 2013; 17(2):147-52. doi: 10.1111/1751-486X.12024.

7. Burke L. The impact of maternal depression on familial relationships. Int Rev Psychiatry. 2003; 15(3):243-55. doi: 10.1080/0954026031000136866.

8. Romano M, Cacciatore A, Giordano R, La Rosa B. Postpartum period: Three distinct but continuous phases. J Prenat Med. 2010; 4(2):22.

9. Pearlstein T, Howard M, Salisbury A, Zlotnick C. Postpartum depression. Am J Obstet Gynecol. 2009; 200(4):357-64. doi: 10.1016/j.ajog.2008.11.033.

10. Sha T, Yan Y, Gao X, Xiang S, He Q, Zeng G, et al. Influential factors for postpartum depression based on the structural equation model in Kaifu District in Changsha. Zhong nan da xue xue bao Yi xue ban= Journal of Central South University Medical sciences. 2017; 42(10):1191-7.

11. Halbreich U, Karkun S. Cross-cultural and social diversity of prevalence of postpartum depression and depressive symptoms. J Affect Disord. 2006; 91(2):97-111.
12. Georgiopoulos AM, Bryan TL, Yawn BP, Houston MS, Rummans TA, Therneau TM. Population-based screening for postpartum depression. Obstet Gynecol. 1999; 93(5):653-7.

13. McCoy SJB, Beal JM, Shipman SBM, Payton ME, Watson $\mathrm{GH}$. Risk factors for postpartum depression: $A$ retrospective investigation at 4-weeks postnatal and a review of the literature. J Am Osteopath Assoc. 2006; 106(4):193.

14. Klainin P, Arthur DG. Postpartum depression in Asian cultures: A literature review. Int J Nurs studies. 2009; 46(10):1355-73. doi: 10.1016/j.jinurstu.2009.02.012.

15. Regmi S, Sligl W, Carter D, Grut W, Seear M. A controlled study of postpartum depression among Nepalese women: Validation of the Edinburgh Postpartum Depression Scale in Kathmandu. Trop Med Int Health. 2002; 7(4):378-82.

16. Parsons CE, Young KS, Rochat TJ, Kringelbach $M$, Stein A. Postnatal depression and its effects on child development: A review of evidence from low-and middle-income countries. Br med bull. 2012; 101(1). doi: $10.1093 / b m b / l d r 047$.

17. O'hara MW, McCabe JE. Postpartum depression: Current status and future directions. Annu Rev Clin Psychol. 2013; 9:379-407. doi: 10.1146/annurevclinpsy-050212-185612.

18. Atif $K$, Ullah $M Z$, Afsheen $A$, Naqvi SAH, Raja ZA, Niazi SA. Son Preference in Pakistan; A Myth or Reality. Pak J Med Sci. 2016; 32(4):994. doi: 10.12669/ pjms.324.9987.

19. Ing $H$, Fellmeth $G$, White J, Stein A, Simpson JA, McGready R. Validation of the Edinburgh Postnatal Depression Scale (EPDS) on the ThaiMyanmar border. Trop Doct. 2017; 47(4):339-47. doi: 10.1177/0049475517717635.

20. Patel V, Ramasundarahettige C, Vijayakumar L, Thakur J, Gajalakshmi V, Gururaj G, et al. Suicide mortality in India: A nationally representative survey. Lancet. 2012; 379(9834):2343-51. doi: 10.1016/S01406736(12)60606-0.

21. Fuhr DC, Calvert C, Ronsmans C, Chandra PS, Sikander S, De Silva MJ, et al. Contribution of suicide and injuries to pregnancy-related mortality in lowincome and middle-income countries: A systematic review and meta-analysis. Lancet Psychiatry. 2014; 1 (3):213-25. doi: 10.1016/S2215-0366(14)70282-2. 
22. Prady S, Kiernan $\mathrm{K}$. The effect of post $\square$ natal mental distress amongst Indian and Pakistani mothers living in England on children's behavioural outcomes. Child Care Health Dev. 2013; 39(5):710-21. doi: 10.1111/j.1365-2214.2012.01426.x.

23. Grace SL, Evindar A, Stewart D. The effect of postpartum depression on child cognitive development and behavior: a review and critical analysis of the literature. Arch Womens Ment Health. 2003; 6(4):263-74.

24. Johnson AR, Edwin S, Joachim N, Mathew G, Ajay $\mathrm{S}$, Joseph B. Postnatal depression among women availing maternal health services in a rural hospital in South India. Pak J Med Sci. 2015; 31(2):408. doi: http://dx.doi.org/10.12669/pjms.312.6702.

25. Parsons CE, Young KS, Rochat TJ, Kringelbach ML, Stein A. Postnatal depression and its effects on child development: A review of evidence from lowand middle-income countries. $\mathrm{Br}$ Med Bull. 2012; 101(1):57. doi: 10.1093/bmb/ldr047.

26. Robertson E, Grace S, Wallington T, Stewart DE. Antenatal risk factors for postpartum depression: A synthesis of recent literature. Gen Hosp Psychiatry. 2004; 26(4):289-95.

27. Hegde $S$, Latha $K$, Bhat $S$, Sharma $P$, Kamath A, Shetty A. Postpartum depression: Prevalence and associated factors among women in India. J Womens Health, Issues Care. 2012; 1:1. doi: 10.4172/23259795.1000101.

28. Husain N, Bevc I, Husain M, Chaudhry I, Atif N, Rahman A. Prevalence and social correlates of postnatal depression in a low income country. Arch Womens Ment Health. 2006; 9(4):197-202. doi: 10.1007/s00737006-0129-9.

29. Golbasi Z, Kelleci M, Kisacik G, Cetin A. Prevalence and correlates of depression in pregnancy among Turkish women. Matern Child Health J. 2010; 14(4):48591. doi: 10.1007/s10995-009-0459-0.

30. Patel V, Rodrigues M, DeSouza N. Gender, poverty, and postnatal depression: A study of mothers in Goa, India. Am J Psychiatry. 2002; 159(1):43-7.
31. Gausia K, Fisher C, Ali M, Oosthuizen J. Magnitude and contributory factors of postnatal depression: A community-based cohort study from a rural subdistrict of Bangladesh. Psychol Med. 2009; 39(6):999-1007. doi: 10.1017/S0033291708004455.

32. Fisher J, Mello MCd, Patel V, Rahman A, Tran T, Holton $S$, et al. Prevalence and determinants of common perinatal mental disorders in women in low-and lower-middle-income countries: A systematic review. Bull World Health Organ. 2012; 90(2):139-49. doi: 10.2471/BLT.11.091850

33. Sikander S, Lazarus A, Bangash O, Fuhr DC, Weobong $B$, Krishna RN, et al. The effectiveness and costeffectiveness of the peer-delivered Thinking Healthy Programme for perinatal depression in Pakistan and India: The SHARE study protocol for randomised controlled trials. Trials. 2015; 16(1):534. doi: 10.1186/ s13063-015-1063-9.

34. Hopkins J, Marcus M, Campbell SB. Postpartum depression: A critical review. Psychol Bull. 1984; 95(3):498.

35. Dennis C-L, McQueen K. The relationship between infant-feeding outcomes and postpartum depression: A qualitative systematic review. Pediatrics. 2009; 123(4):e736-e51. doi: 10.1542/peds.2008-1629.

36. Swendsen JD, Mazure CM. Life stress as a risk factor for postpartum depression: Current research and methodological issues. Clinical Psychology: Science and Practice. 2000; 7(1):17-31.

37. Chandran M, Tharyan P, Muliyil J, Abraham S. Postpartum depression in a cohort of women from a rural area of Tamil Nadu, India. Br J Psychiatry. 2002; 181(6):499-504. doi: 10.1192/bjp.181.6.499

38. Nnadi I. Son preference-a violation of women's human rights: A Case Study of Igbo Custom in Nigeria. J Pol \& L. 2013; 6:134.

39. O'mahen H, Richards D, Woodford J, Wilkinson E, McGinley J, Taylor RS, et al. Netmums: A phase II randomized controlled trial of a guided Internet behavioural activation treatment for postpartum depression. Psychol Med. 2014; 44(8):1675-89. doi: 10.1017/S0033291713002092. 


\begin{tabular}{|c|c|c|c|}
\hline \multicolumn{4}{|c|}{ AUTHORSHIP AND CONTRIBUTION DECLARATION } \\
\hline Sr. \# & Author(s) Full Name & Contribution to the paper & Author(s) Signature \\
\hline 1 & Afeera Afsheen & Manuscript writing. & \\
\hline 2 & Khaula Atif Khan & Conceoption and search. & \\
\hline 3 & Javaria Nosheen & Proof reading, Literature & \\
\hline 4 & Sobia Mehreen & $\begin{array}{l}\text { review. } \\
\text { Review. }\end{array}$ & \\
\hline 5 & Rabiah Anwar & Literature review. & alsiets \\
\hline 6 & Bushra Iftikhaar & Litereture review. & \\
\hline
\end{tabular}

